\author{
Professor Nora CHIRIŢĂ, PhD \\ E-mail : nora.chirita@csie.ase.ro \\ Department of Economic Informatics and Cybernetics \\ The Bucharest University of Economic Studies \\ Associate Professor Cristian CIUREA, PhD \\ E-mail: cristian.ciurea@ie.ase.ro \\ Department of Economic Informatics and Cybernetics \\ The Bucharest University of Economic Studies \\ Assistant Ionuț NICA, PhD \\ E-mail: ionut.nica@csie.ase.ro \\ Department of Economic Informatics and Cybernetics \\ The Bucharest University of Economic Studies
}

\title{
AN ANALYSIS OF INVESTMENT DECISIONS FROM IC\&T INDUSTRY IN THE CONTEXT OF BEHAVIORAL ECONOMY
}

\begin{abstract}
The analysis and investigation of investment decisions is another topic of interest for economic actors who want to know the stock market and invest in shares from which to make a profit. In this sense, we consider that behavioral economics and its characteristics play an important role in studying the behavior of investors when they make important decisions. With the help of the $R$ Studio and Altreva Adaptive Modeler program, the stock market was analyzed and simulated for 5 well-known companies: Microsoft, Oracle, Accenture, Cisco, Intel and IBM. Behavioral economics provides an ideal framework for understanding when and how agents make mistakes and how they or systematic biases predictably occur under certain conditions or circumstances. The concepts offered by this field can be used to build environments that encourage people to make wise decisions, considering the dynamic environment in which their actions are performed.
\end{abstract}

Keywords: Behavioral Economics, Stock Market, $R$ Studio, Altreva Adaptive Modeler.

JEL Classification: G11, G17, G41, E47

\section{Introduction}

The economy, in general, can be described as a complex adaptive system which include all systems such as businesses, banks, public institutions, financial markets and characterized by interdependencies created and how they evolve, adapt and react to changes in the environment, according to (Nica \& Chiriță, 2020).

DOI: 10.24818/18423264/55.2.21.10 
Actors or players who undertake economic activities, also known as economic agents, regardless of their classification, are the key element both at the level of an enterprise and at the level of a market. The behavior of economic agents influences the evolution of an economic system according to (Lewis et al, 2008), thus represented an important and decisive factor.

It is known that the environment in which agents operate is uncertain, characterized by the evolution of several factors such as social, political, technological, macro or microeconomic, legal, environmental or ethical. In this environment, the behavior of an economic actor can be modelled and his behavior has an influence on strategic decisions that can be addressed when analyzing a system or the decision to make an investment, according to (Chiriță \& Nica, 2019).

Behavioral economics provides an ideal framework for understanding when and how agents make mistakes and how they or systematic biases predictably occur under certain conditions or circumstances. The concepts offered by this domain can be used to build environments that encourage people to make wise decisions, considering the dynamic environment in which their actions are performed, according to (Tversky \& Kahneman, 1974).

In this research it was proposed to analyze the way in which the agents make investment decisions having at their choice several companies that are analyzed and diagnosed with the help of computer programs. Having these results available, it will be studied how their behavior will be influenced and how their investment decision will be influenced.

The enterprise is the most eloquent example of a complex and adaptive system, presenting all the properties it respects, such as emergence, connectivity, co-evolution or self-organization. Due to the way it works and the existing relationships, the company is obviously a cybernetics system.

Thus, six companies from IC\&T industry will be diagnosed which are complex adaptive systems by their nature and by the properties they fulfil such as connectivity, interdependence, coevolution or emergence.

\section{Behavioral Economy and Behavioral Characteristics Regarding Investment Decision Making}

Behavioral economics aims at understanding economic behavior and the impact it would have on an economic system. Specifically, the field of study of behavioral economics aims to understand concepts and decisions based on the behavior of individuals, such as understanding why we go to work, why we save for retirement, why we make donations or what are the reasons for the decision to sell a car or why you can't quit smoking. In addition, it studies how people make rational, wise choices or less good decisions. It is difficult to say when behavioral economics emerged as a field of study, but many researchers say that.

Adam Smith was the founder of these field and in the book "The Theory of Moral Sentiments" explains why people are not only motivated by their own 
An Analysis of Investment Decisions from IC\&T Industry in the Context of Behavioral Economy

interest, but have also developed a natural sense of empathy, describes why reward is important but also punishment in (Smith, 2007). So, Adam Smith describes a lot of concepts that in recent years have become major problems in behavioral economics. Even if at that time there was no awareness of this, psychology and economics were often interconnected. For example, a fundamental principle of the law of diminishing marginal utility is based on psychological ideas.

Meanwhile, several economists, including Pareto, have developed mathematical theories for rational choice. Even though for many years there was an attempt to abandon the psychology used in economic concepts, after the 1960s, their interdependence and connectivity returned. Daniel Kahneman and Amor Tversky are considered some of the most important scientists who laid the foundations of recent behavioral economics.

(Trémolière \& De Neys, 2014) believes that intuitions are often considered sub-optimal and can influence people's thinking in choosing optimal strategies.

(Zeliler \&Teitelbaum, 2018) believes that the field of behavioral economics has greatly contributed to the understanding of economic agents in decision making by refining neoclassical hypotheses.

Although psychology has been widely criticized when it was considered important in economic choices or economics, its principles govern people's perceptions and how they treat decision-making issues or evaluate strategic choices. The principle of rationality, the key element between the economic and psychological connection, must meet fundamental requirements regarding accuracy, coherence, precision and consistency. Usually, economic agents violate the fundamental principles of psychology and this must be improved, i.e. the economy must be shaped by behavioral theory to increase the performance of economic objectives that can be set both micro-economically and macroeconomically.

The efficiency of the capital markets, the impossibility to obtain the performance above the market level for a long period of time and the rationality of the investors are 3 concepts considered by the generally valid classical finance theory. When investors build profitable portfolios, they can build this portfolio as a mix of assets in order to obtain the best possible return considering the degree of risk of each asset, a degree that does not exceed the values tolerated by the investor. The efficient markets hypothesis consists in the premise that economic actors have access to information, prices, asset evolutions, highlighting the importance and influence of available information, according to (Goodwin et al, 2013) and (Minton \&Khale, 2013).

To achieve success on the stock market, there is a set of features that an investor must acquire such as understanding the internal mechanisms, the ability to anticipate the meaning of a trend, but also keeping temperance to the influence of emotions in trading.

Despite the fact that the investment experience, specialized studies and the size of the capital involved are basic aspects characteristic of a successful player,

DOI: $10.24818 / 18423264 / 55.2 .21 .10$ 
Nora Chiriță, Cristian Ciurea, Ionuț Nica

the psychological factor that is often ignored proves to be very important, especially in situations where it is necessary to take setback decisions. So, there are a number of relevant psychological factors that need to be considered because they can affect success in the investment market: herd effect, overestimation of own investment skills and market preconceptions, according to (Hommes, 2012) and (Lowe \& Teece, 2001).

\section{Modelling with Altreva Adaptive Software}

Some time ago, instead of capitalizing on complexity, people were trying to avoid it by approaching the task of modelling financial markets. Moreover, a result provided by a simplified model has a high probability of predicting pertinent and rational results that are contradictory with the existent behavior that markets possess. Yet creating an agent-based market model, such as a virtual market, will create an opportunity for me to exploit its complexity and use it in the functions that will result as an effect of the model, like emerging behavior, to predict the time series formulated on a real financial model, and the ability to produce wealth. An example of real data analysis in order to develop an index score for the internal auditor profile in Romania was presented in (Mocanu \& Ciurea, 2019).

Altreva Adaptive Modeler creating financial market simulation models based on agents become possible, the simulation giving a hand of help in predicting the prices of shares that were traded on the real market or other currencies, securities, cryptocurrencies, the latter group being traded on a specific market. That software uses a technology established on the theory of economy based on agents, the study of calculating economic processes which were modelled as dynamic systems with the help of heterogeneous agents. With the usage of Altreva, an adaptive model, and other models based on agents, simulation of financial market can be realized in order to capture the complex dynamics of a high variety of investors and traders, each of them with its own strategy, trading in different periods of time and having distinctive objectives. Learning models, which consist of characteristics like being an agent-one, heterogeneous and rational, are more capable of explaining the empirical characteristics of financial markets than the traditional financial models, this because the fact that the traditional models are being dependent on representative rational agents. The software is capable of creating an agent-based model for some specific stock, the model itself consisting of an agent population and a fictional (virtual) marketplace. Each of the agents can be seen as a virtual trader or investor, having its own trading rule and funds.

Starting from the idea that the definition of an agent starts from the definition of intelligence, as Carl Hewitt, a specialist in artificial intelligence, states, an agent can be treated in a broad or narrow sense. In the first variant, the agent is used as a calculation system that fulfils the following properties: autonomy (agents operate without other system or other people intervening directly), social ability (agents interact with other agents), reactivity (agents perceive the environment surrounding). 
An Analysis of Investment Decisions from IC\&T Industry in the Context of Behavioral Economy

Agent-based modelling is based on simulating the actions and interactions of several people or organizations in order to analyze emerging effects on a system. An agent-based financial market model, for example, consists of a population of agents (investors) and a mechanism for regulating stock prices.

The model based on agents strongly relies on simulating the interactions and actions of some people or organizations, its scope being the analysis of the emerging effects which occur on a system.

For instance, an agent-based model of a financial market, is constituted by a population of agents (investors) and a mechanism that regulates the stock prices. Any traditional financial model can be surpassed by an agent-based model, which can explain in a better way the behavior of the financial market. With the help of either analytical mathematics or econometric models, financial markets could be studied, the pile of this statement being the fact that usually, the market participants were considered as rational individuals.

Adaptive Modeler make usage of computational intelligence and is mainly designed to market indices or actively traded stocks, i.e. using futures contracts.

\section{Building a Speculative Trading Model Based on the Adaptive Behavior of Economic Agents}

Describing the behavior of financial markets in a better way than the traditional models can be achieved by building a speculative trading model which relies on the adaptive behavior of economic agents. With the help of the agentbased modelling methodology and also Altreva software application, the behavior of the agents becomes noticeable, therefore certain prices and certain trading signals can be forecasted.

By using an agent-based modelling methodology, we could point out the fact that the agents, which are acting adaptively and endogenously, create a persistent price bubble. The dynamics of the price generated by the process of trading do not reveal any particularity, still the process goes along with an increase in aggregate risk, which show a raise in an accident's probability, according to (Chiriţă \& Nica, 2020).

It will be taken in consideration a model of economic behavior based on agents. It is described by behavioral traits common of exchange patterns, characterized by either an individual or a group behavior. The idea that agents possess a common belief that it is in their advantage to participate in the market activity is described by the ownership of group behavior. Under other conditions, the individual behavior can be characterized by the further properties: each of the agents acts in his own interest; agents own heterogeneous preferences; optimal and reciprocal outcome can be achieved by the interactions of the agents; agents have a behavior which is adaptive;

In the Altreva simulation, noted with $t=0,1,2 \ldots, n$. will be the supposed meeting at intervals of the agents.

DOI: 10.24818/18423264/55.2.21.10 
Basically, an agent has a portfolio which can be described by the stockbond relationship, denoted by $\left(a_{i}^{t}, o_{i}^{t}\right)$, representing an agent $i$ trading at some specific time $t$. With $p^{t}$, will be denoted the price of a share at time.

The following moment, the player is characterized by a portfolio $\left(a_{i}^{t+1}, o_{i}^{t+1}\right)$ and also by the price per share $p^{t+1}$ contained in that portfolio. Laying out the latest changes which appeared in the agent's portfolios, it will be taken in consideration that, for the next period, they set goals based on the stockbond ratios, which will be marked with $x_{i}^{t+1}$. To better understand the relations between agents, it will be supposed that another agent will exist $\left(a_{j}^{t}, o_{j}^{t}\right)$, sharing the same portfolio, according to the approach proposed by Misha Prepelitza.

Considering this approach, it is assumed that the new price $p^{t+1}$ is set in a way that the agent wants to move its dollar amount from shares to bonds, and the target ratio is the same as the dollar amount that the agent wants to move from bond to shares, and the target ratio $x_{i}^{t+1}$ of agent to be. The balance can be interpreted using the following relation:

$$
\frac{p^{t+1}}{p^{t}} * a_{i}^{t}-x_{i}^{t+1} * o_{i}^{t}=x_{j}^{t+1} * o_{j}^{t}-\frac{p^{t+1}}{p^{t}} * a_{j}^{t}
$$

The two players $i$ and $j$, agent issues different opinions and behaviors on market performance. The target portfolio results should be updated in accordance with the next rule:

$$
x_{k}^{t+2}=\left\{\begin{array}{c}
\alpha * x_{k}^{t+1} * \frac{p^{t+1} * a_{k}^{t}}{p^{t} * o_{k}^{t}}>x_{k}^{t+1} \\
x_{k}^{t+1} * \frac{p^{t+1} * a_{k}^{t}}{p^{t} * o_{k}^{t}}=x_{k}^{t+1} \\
\gamma * x_{k}^{t+1} * \frac{p^{t+1} * a_{k}^{t}}{p^{t} * o_{k}^{t}}<x_{k}^{t+1}
\end{array}\right.
$$

The parameters that could possibly define a feedback mechanism of a complex adaptive system are $\gamma \in(0,1)$ and $\alpha>1$. If a growing market is identified by the agent, it will increase its own ratio of shares to bonds by a set amount, while the other agent is reducing its ratio. The feedback shows the fact that when an agent is facing with a series of weak investments, it will diminish the share of capital in the portfolio, while if the investment grows more than expected, he will position himself in a riskier way.

Additionally, to the price charts, agent-based models show significant information on the distribution of wealth between agents. This information offers the possibility of studying of the effects of market activity on the population consisted of agents. Thus, in the analysis which was performed in the section dedicated to the case study, data was collected based on the next actions: Cisco, IBM, Intel, Microsoft, Oracle and Accenture. 
An Analysis of Investment Decisions from IC\&T Industry in the Context of Behavioral Economy

\footnotetext{
A model based on agents consists of a computational model which simulates the actions and interactions of multiple agents to help the analysis of the effects on a complex system considered as a whole and it is a useful tool in understanding trading behavior and markets. An agent-based financial market model is represented by a population of agents (or investor representatives), a price discovery and mechanism of clearing (representing a virtual market).
}

\section{Case Study for IC\&T Companies}

The companies proposed for analysis and submission to investment decisions of agents are: IBM, Microsoft, Oracle, Accenture, Intel and Cisco. The software programs used to make the diagnosis are Altreva Adaptive Modeler and the R Studio program.

IBM Corporation provides advanced technology, hardware products, cloud-based software services, is headquartered in New York and has many departments around the world. It was founded by Charles Ranlett Fitt in 1911, following the merger of four companies in New York, called ComputerTabulating-Recording Company and later, in 1924, International Business Machines.

Microsoft, like IBM, is an American corporation, a global leader in software production, based in Washington, USA. The company develops software applications, licenses them and maintains several varieties of services, generally services applied to computers. Founded by Paul Allen and Bill Gates on April 4, 1975 , the corporation became well known when it was the market leader with the MS-DOS operating system and later Windows. The Microsoft Office suite also belongs to the corporation, dominating the market this time as well.

The third company seen as a complex adaptive system is Oracle, an American corporation based in California. Larry Ellison, Bob Miner and Ed Oates are the founders of Oracle, laying its foundations in 1977. The corporation produces software and technologies specific to databases, cloud design systems and develops brands specific to various database management systems enterprises.

In terms of market capitalization and revenue, according to available information, in 2019 Oracle is considered the second software company.

Unlike the companies presented above, the multinational Accenture is based in Dublin, Ireland, founded in 1989 by Arthur Anderson, with the original name of Arthur Andersen Business Consulting. In 2001 the company was named Accenture starting from the concept of "Accent on the Future".

The corporation declares in 2019 a number of 505.000 employees and a net income of 4.78 billion dollars. The consulting services and software they offer are distributed in more than 200 cities in 120 countries.

The American company Intel is the global leader in the production of semiconductors and the one that invented x86 processors. It was founded in 1968 by Robert Noyce and Gordon Moore and is based in California, United States. The

DOI: 10.24818/18423264/55.2.21.10 
corporation manufactures processors, network cards, graphics cards and other computer-specific hardware.

The multinational Cisco System is of American origin based in California, United States of America. The company develops and markets both software and software products, telecommunications equipment and high-tech products.

It was founded by Sandy Lerner and Leonard Bosack in 1984, has a net income of $\$ 11.62$ billion and a number of 75,900 employees, data reported in 2019.
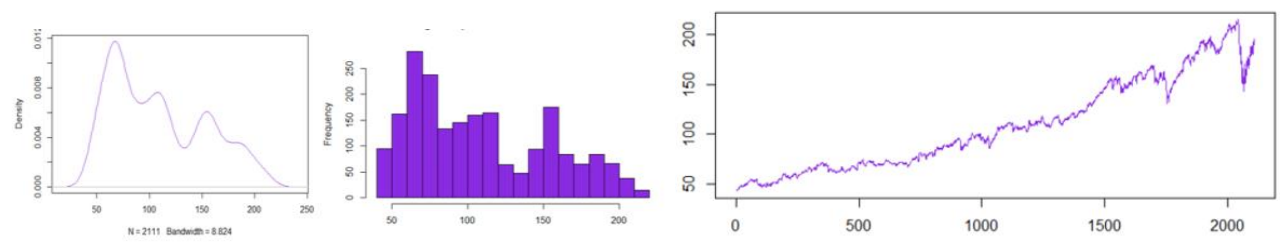

Figure 1. Probability density, closing price histogram of an Accenture stock and the evolution over time of the closing price of a share of Accenture company

Source: our own computation

Analyzing the probability distribution, respectively the histogram of the series of records representing the values of the daily closing price of a share of Accenture, we observe an asymmetric distribution of the price, predominating the small values, located to the left of the average, the most frequent values it took on the time horizon were between $\$ 50$ and $\$ 100$. Considering the graph above, in which we highlighted how the price of an Accenture share fluctuated over the period 2012-2020, we identify several relevant aspects in the proposed analysis, namely: there is an increasing trend with a steep slope, strictly reporting the current situation to the initial situation, the price of a share has increased 4 times, starting from a value of about \$ 50 in 2012 and exceeding the threshold of \$ 200 in 20192020, which can be interpreted by the fact that Accenture is a very profitable company, in full development, a healthy company that offers many opportunities in the future through its growth rate and stability. However, we identify two periods over the time horizon in which there were exceptions to the upward trend. The first period in which closing prices were on a downward slope was influenced by the $15 \%$ decrease in the market index of the New York Stock Exchange, the S\&P 500 as a result of statements and pressure on the Federal Reserve. of the United States and the policies advocated by US President Donald Trump. During his tenure, there were 7 interest rate increases, hampering the lending process of banks. The second difficult period that also affected Accenture was recorded in March-April 2020 as a result of the global economic recession caused by the Coronavirus pandemic that forced states to impose containment measures, hindering the normal conduct of economic activities in business and government environment. 
An Analysis of Investment Decisions from IC\&T Industry in the Context of Behavioral Economy
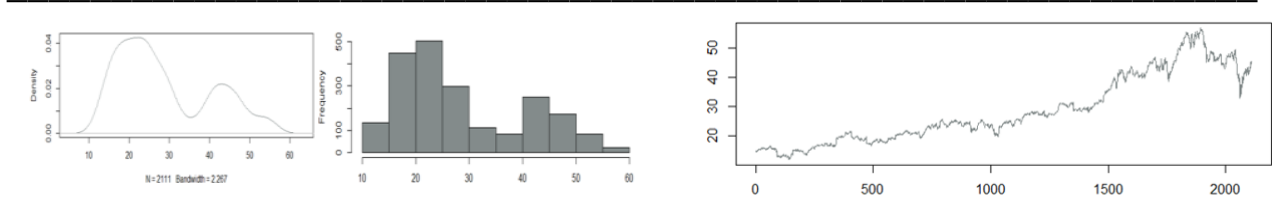

Figure 2. Probability density, closing price histogram of a Cisco stock and the evolution over time of the closing price of a share of Cisco company

Source: our own computation

According on the figure above, which describes the probability density and the histogram distribution of the closing price values of a Cisco stock, an asymmetric distribution is observed in which the values below the average predominate. There are two modal ranges, one wider with values between $\$ 10$ and $\$ 30$, most values in the series can be included here, and a moderate one representing values between $\$$ 40 and $\$ 50$. Considering the chosen time horizon, we can say that the closing price follows a slightly upward trend in 2012-2017, and then a slightly more pronounced one which, like the previously analyzed company, recorded 2 major disruptions in October-December 2018 due to the recession American banks and Federal Reserve issues. Between March and April 2020, the evolution is impacted by the context of the Coronavirus pandemic, but although these periods were difficult for all companies worldwide, Cisco has always managed to rectify the situation in a very short time. As a general aspect for the entire analysis period, the Cisco price doubled from 2012 to 2020, registering even on July 15, 2019 the highest value in the last 20 years, $\$ 56.65$, currently hovering around the price of $\$ 40$.
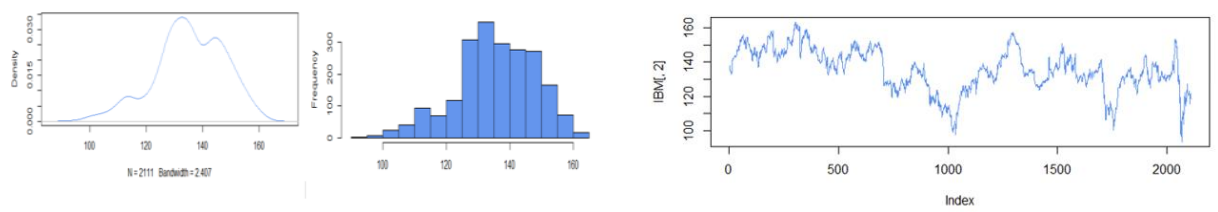

Figure 3. Probability density, closing price histogram of an IBM stock and the evolution over time of the closing price of a share of IBM company

Source: our own computation

Analyzing IBM company, we notice that the trend component of the closing price evolution is missing, there are also many peaks, both positive and negative, the most important of which are the 3 negatives in which the values have reached the minimum threshold of 100, and those in the second part of the analysis in which there were significant increases approaching the value of $\$ 160$. We can analyze the separate chart over 2 time periods: one for the years 2012-2014 characterized by very high values of the closing price in the area of 150-160 dollars and stability, and the second period much more tumultuous with countless increases and decreases. In the years 2015-2016, IBM adapted more difficult to the 
needs of customers in terms of cloud computing services, offering, according to a team of Deutsche Bank specialists, services of low quality and at much higher prices than the main competitors Amazon and Microsoft. But the company approached a proper policy and managed to blur this gap, and even return very quickly to an upward trend, reaching again the value of $\$ 150$ by the end of 2016 . The other two major events that led to significant declines have was as in the case of most companies listed on the New York Stock Exchange the crisis of the US Federal Reserve and the recession caused by the spread of Coronavirus this year.
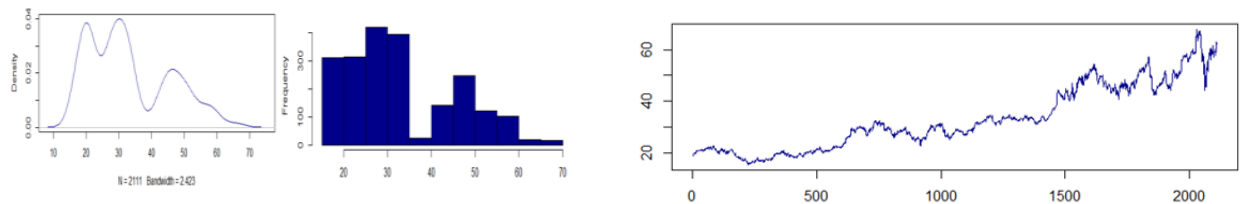

Figure 4. Probability density, closing price histogram of an Intel stock and the evolution over time of the closing price of a share of Intel company

Source: our own computation

Based on the probability density and the closing price histogram of Intel, we deduce that the values describe an asymmetric distribution on the left, most of the records being below average, as evidenced by the histogram based on which a concentration of values can be seen in the graph above. In the period $2012-2020$, the evolution of the closing price values of Intel shares was analyzed and we can observe that there is certainly an upward trend throughout the time frame, much more stable than in the case of the other companies included in the portfolio, with very few fluctuations. The only mention worth mentioning is the rapid negative impact that the recession caused by the Coronavirus pandemic had on the evolution of the closing price during March-April 2020.
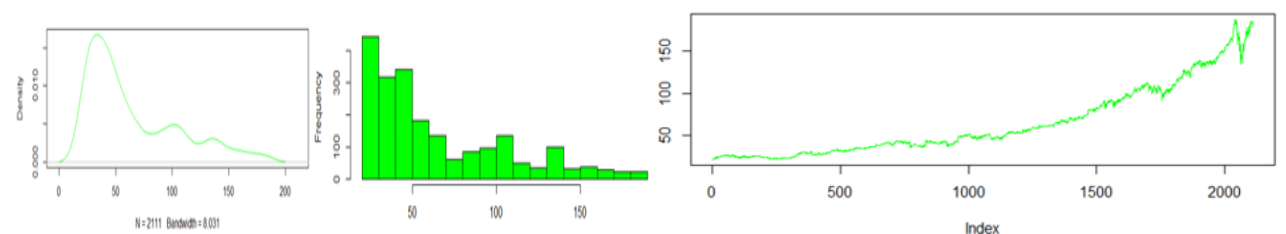

Figure 5. Probability density, closing price histogram of a Microsoft stock and the evolution over time of the closing price of a share of Microsoft company

Source: our own computation

Microsoft follows the model of the companies included in the paper by presenting a negative asymmetric distribution, with low values in a high percentage, the modal value being around $\$ 30$. In the graph above, we can observe the evolution of Microsoft's closing price who indicates by far the highest growth rate of all companies, representing one of the giants worldwide. In the period 2012- 
An Analysis of Investment Decisions from IC\&T Industry in the Context of Behavioral Economy

2020 it managed to increase by up to 10 times in terms of the closing price, growing very quickly and evenly managing not to be affected by events that put other companies in difficulty, even in terms of the pandemic of Coronavirus.
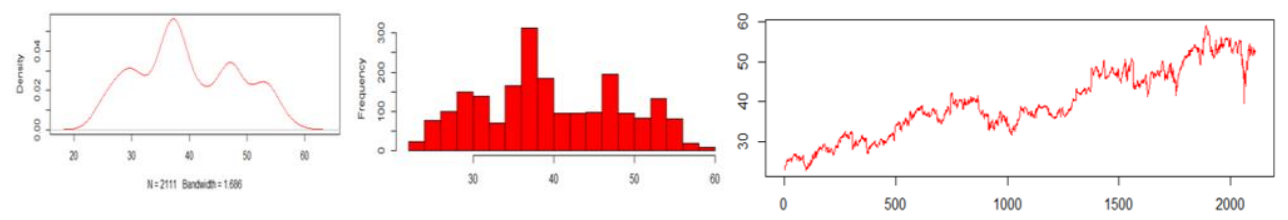

Figure 6. Probability density, closing price histogram of an Oracle stock and the evolution over time of the closing price of a share of Oracle company

Source: our own computation

Oracle is closest to a symmetrical model of probability density, the values being located around the average on either side of it, the most common values of the closing price of the shares being in the area of $\$ 35$. Following the analysis made on figure 6 , there is an increasing trend with very small fluctuations, managing to double the value of shares in the selected analysis period. Like other companies, it was seriously affected by the economic impact of the new Sars-Cov2 virus in the spring of 2020 .

Table 1. Correlation Matrix

\begin{tabular}{ccccccc}
\hline Companies & Accenture & Cisco & IBM & Intel & Microsoft & Oracle \\
\hline Accenture & 1 & 0.58 & 0.62 & 0.53 & 0.61 & 0.58 \\
Cisco & 0.58 & 1 & 0.54 & 0.56 & 0.58 & 0.58 \\
IBM & 0.62 & 0.54 & 1 & 0.51 & 0.54 & 0.55 \\
Intel & 0.53 & 0.56 & 0.51 & 1 & 0.63 & 0.53 \\
Microsoft & 0.61 & 0.58 & 0.54 & 0.63 & 1 & 0.57 \\
Oracle & 0.58 & 0.58 & 0.55 & 0.53 & 0.57 & 1 \\
\hline
\end{tabular}

Source: our own computation

The correlation matrix describes the links that are established between the returns of the analyzed companies included in the portfolio that we set out to achieve, emphasizing in some cases similar evolutions of the companies. We can say that between all 6 companies we find a direct connection, of medium intensity, the correlation coefficient takes values between 0.3 and 0.7 . The weakest link is established between IBM and Intel because they are direct competitors, and at the opposite pole we find the closest link between Intel and Microsoft because they produce complementary products. The conclusion we can draw is that companies will evolve to a large extent in the same direction and will also be affected by the same phenomena proportionally. These explanations are supported by another property of the complex adaptive system, suboptimality.

DOI: 10.24818/18423264/55.2.21.10 
Nora Chiriță, Cristian Ciurea, Ionuț Nica

Table 2. Analysis of investment portfolios based on the criteria: Return of investment, Risk, Sharpe Rate

\begin{tabular}{cccc}
\hline Companies & Return & Risk & Share Rate \\
\hline Accenture & 0.00080 & 0.01428 & 0.05622 \\
Cisco & 0.00066 & 0.01593 & 0.04157 \\
IBM & 0.00002 & 0.01405 & 0.00187 \\
Intel & 0.00072 & 0.01780 & 0.04044 \\
Microsoft & 0.00113 & 0.01612 & 0.07045 \\
Oracle & 0.00508 & 0.01521 & 0.03344 \\
\hline
\end{tabular}

Source: our own computation

Following the analysis of Accenture, Cisco, IBM, Intel, Microsoft and Oracle, we obtained in all cases positive average returns in the time horizon 3/1/2012 22/5/2020. Observed the highest value for Microsoft with a value of $0.1 \%$, followed by Accenture with $0.08 \%$, for Intel the value is $0.07 \%$, for Cisco 0.06 , while Oracle has had an average profitability of $0.05 \%$, at the opposite pole is Microsoft with the lowest profitability resulted IBM with an average value of $0.0002 \%$. Within the investment portfolios, the risk of is given by the fluctuations of the closing price values of the shares, so that for the numerical representation of the degree of risk we use the square average deviation. The companies obtained close values for the degree of risk, namely: IBM and Accenture have the most stable evolution with $14 \%$, followed by Cisco and Oracle with $15 \%$, Microsoft has an average square deviation of $16 \%$, and the largest variations were encountered in the evolution of the closing price of Intel's stock with a value of 17\%. The Sharpe rate is an indicator of the performance of a portfolio, calculated as the ratio between the average return and the mean square deviation. The aim of a portfolio is to obtain a Sharpe rate as high as possible. So, we will present the companies in descending order of the Sharpe rate to see the importance of each in the portfolio. In the case of Microsoft, we obtained a value of 0.07, for Accenture a value of 0.05, 0.04 for both Intel and Cisco, and for Oracle it reached the value of 0.03.

Through the Altreva software solution, it was researched whether a growing market can be identified. Thus, graphs were designed to analyze this. According to the research carried out by the authors Nora Chirita \& Ionut Nica, presented in the article "Analysis of the impact generated by COVID-19 in banking institutions and possible economic effects through agent-based modeling we can see detailed information on how it is distributed wealth between economic agents. With the help of this information, one can analyze the effects they transmit to the market activity on the population of economic players. Agent-based modeling of the financial market is described by a population of agents that is represented by investors and a mechanism that describes the virtual market. The importance of agent-based modeling lies in the fact that it successfully reproduces the behavioral characteristics of time series, such as the mode of leptokurtic distribution or the description of grouped volatilities. Traditional financial models do not explain as

DOI: $10.24818 / 18423264 / 55.2 .21 .10$ 
An Analysis of Investment Decisions from IC\&T Industry in the Context of Behavioral Economy

much information as agent-based financial models. Analytical mathematics applied to market participants is conventionally used to characterize financial markets.

In the figures below we have represented the evolution of the portfolios of Oracle, IBM, Cisco, Microsoft, Intel and Accenture for the period May 2010 April 27, 2020, simulating the model from March 2012. We assumed a population size of 2000 agents, with an equal initial distribution of wealth and a starting capital of 100.000 units. The result of agent-based modeling is seen in the figures below.

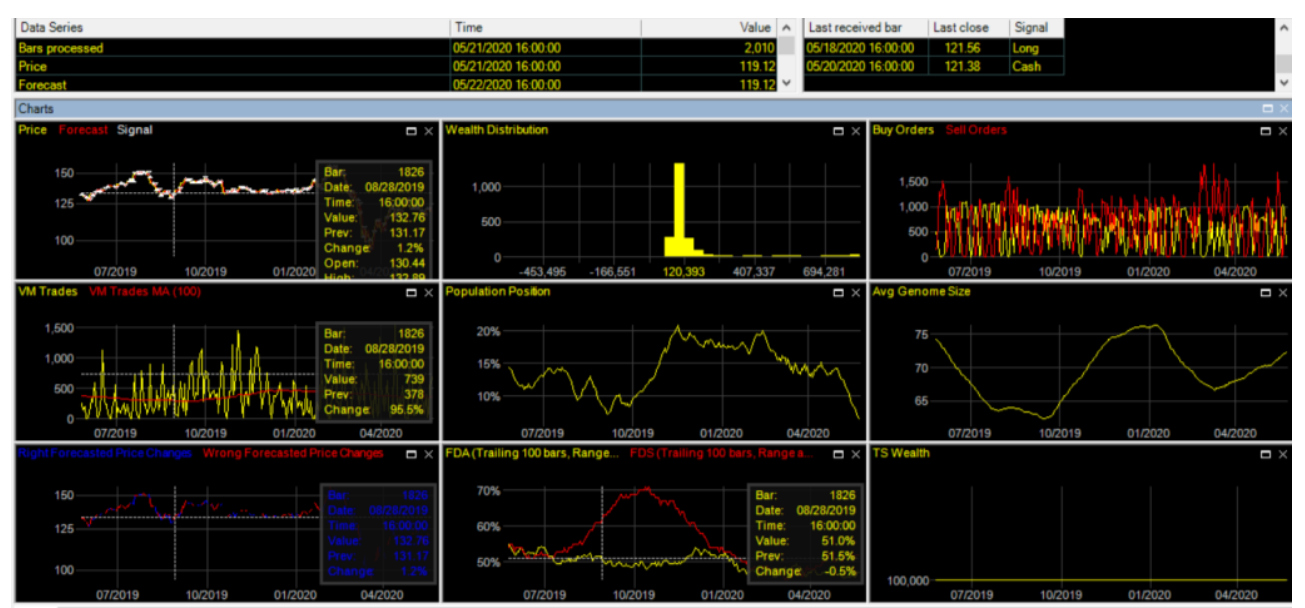

Figure 7. IBM closing price simulation (Altreva Adaptive Modeler)

Source: our own computation

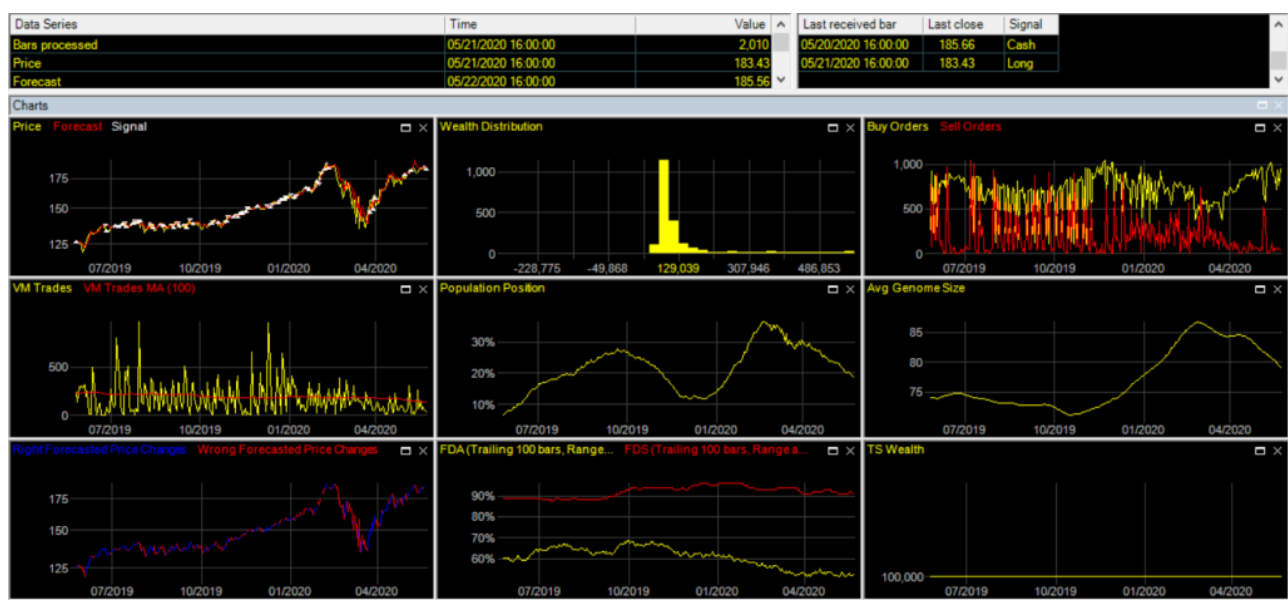

Figure 8. Microsoft closing price simulation (Altreva Adaptive Modeler)

Source: our own computation

DOI: 10.24818/18423264/55.2.21.10 
Nora Chiriță, Cristian Ciurea, Ionuț Nica

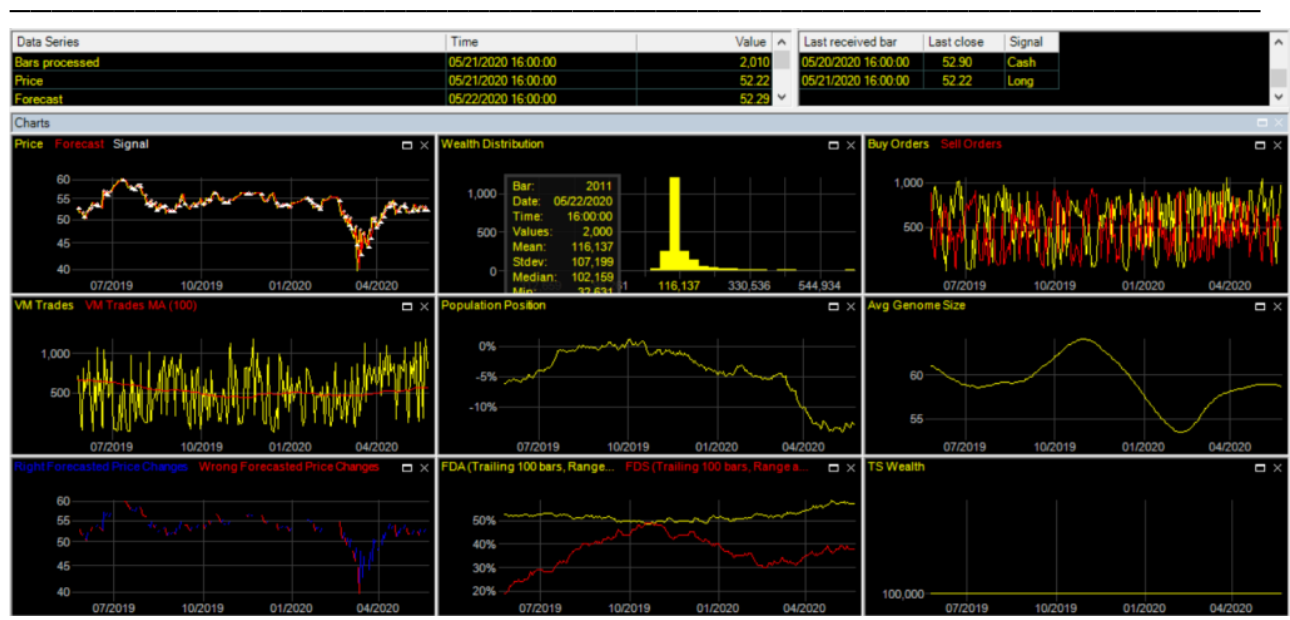

Figure 9. Oracle closing price simulation (Altreva Adaptive Modeler)

Source: our own computation

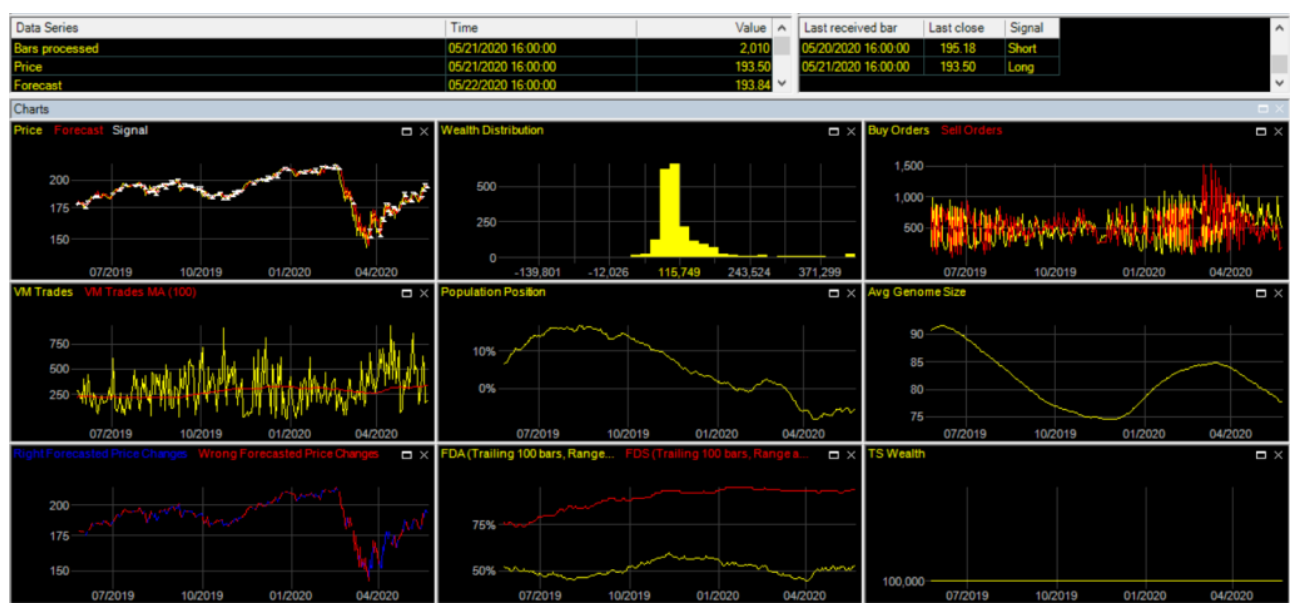

Figure 10. Accenture closing price simulation (Altreva Adaptive Modeler)

Source: our own computation 
An Analysis of Investment Decisions from IC\&T Industry in the Context of Behavioral Economy

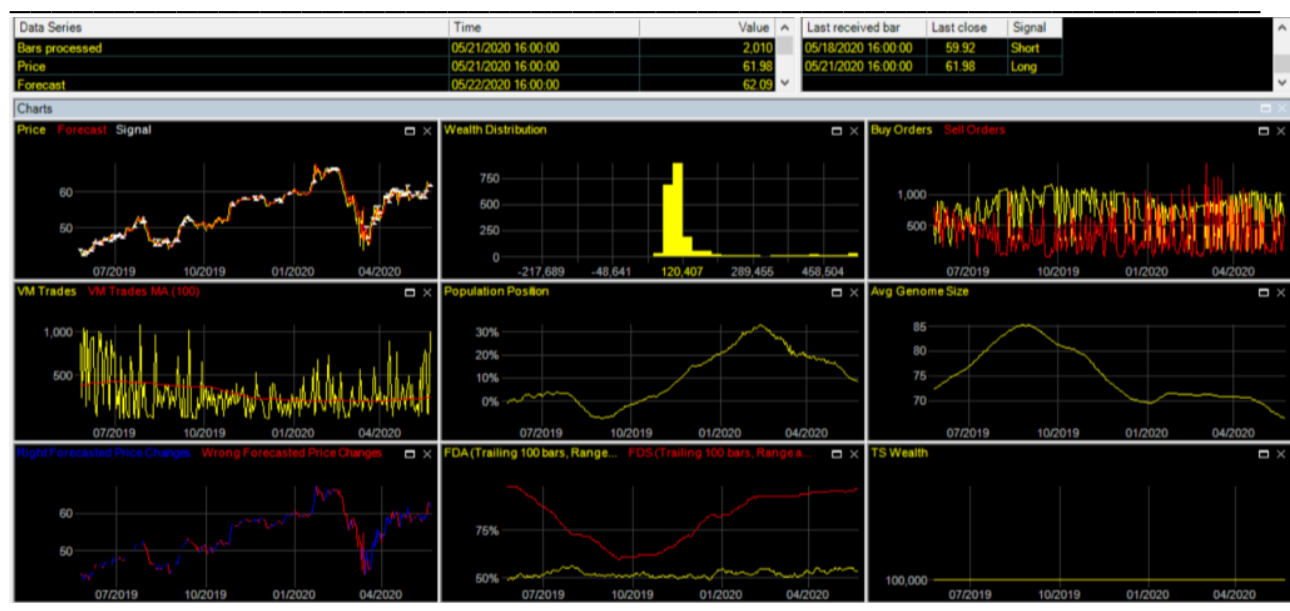

Figure 11. Intel closing price simulation (Altreva Adaptive Modeler)

Source: our own computation

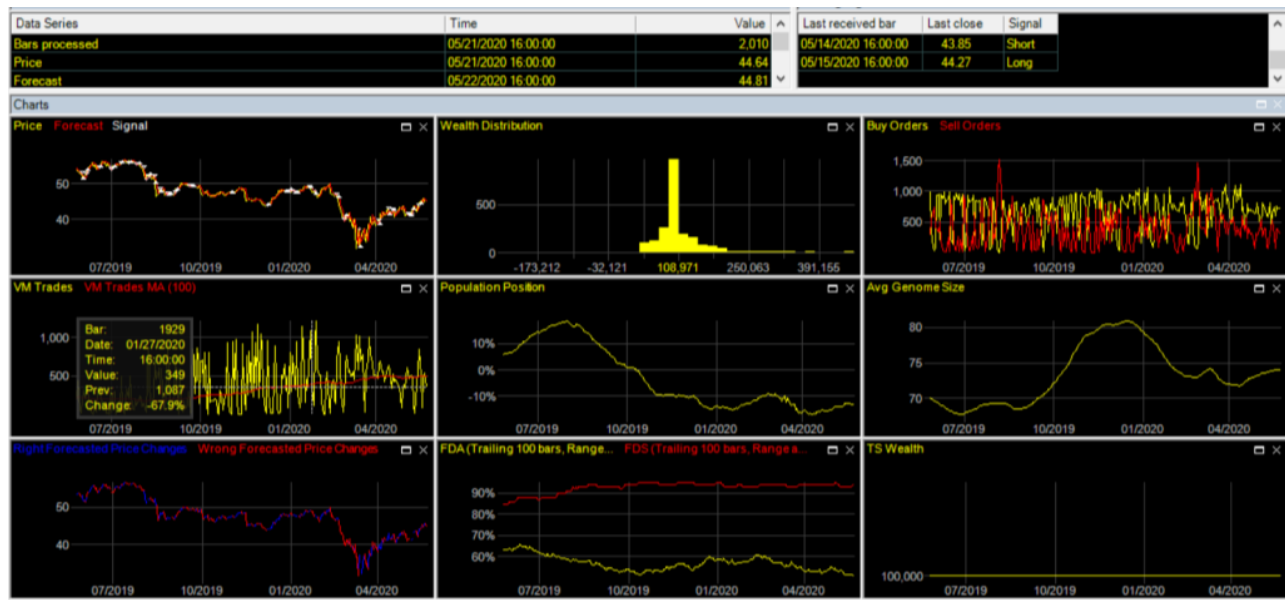

Figure 12. Cisco closing price simulation (Altreva Adaptive Modeler)

Source: our own computation

Adaptive Modeler uses computational intelligence and is primarily designed to actively traded stocks or market indices, i.e. using futures contracts. The simulator works as follows: it is divided into 2 main areas of analysis, agentbased modeling and trading system. In short, the agent-based model receives quotes and produces price forecasts, and the trading system decides when it should give a new trading signal based on the user's forecasts and trading preferences. The analyzed results were exposed to a number of 208 agents who wanted to invest in the near future in the shares of some companies. The respondents had to answer a question from the questionnaire to which they had to give a grade to the 6 companies, on a scale from 1 to 10 , a note that took into account several factors

DOI: 10.24818/18423264/55.2.21.10 
Nora Chiriță, Cristian Ciurea, Ionuț Nica

such as their experience, knowledge in the investment field or risk aversion. The results can be observed in the table below for the $\mathrm{t}=0$ reference index. Subsequently, we conducted a test for 4 other respondents to study more clearly how investors can change their behavior regarding making a decision in conditions of incomplete information, in conditions of certainty or based on instinct or degree of knowledge. In the first scenario, the 4 respondents were asked to give grades from 1 to 10 to the analyzed companies, without providing them with any information. The results can be observed for $t=1$. For $t=2$ we informed the respondents that in the period 2012-2020 the Accenture company had the highest average profitability of closing prices, compared to CISCO, INTEL, IBM, ORACLE. We asked him to give notes taking into account this information. In the following scenario we wanted to investigate whether the following information changes the rating from $t=1$ : In April 2020 Arwind Krishna is appointed the new CEO of IBM. This change led to an increase in the share price for April from $\$ 110$ to $\$ 130$. The final results of this scenario are related to $t=3$. In the last scenario, the graphs made in $\mathrm{R}$ and Altreva Adaptive Modeler were made available to see how they influence the decision of the potential investor.

Table 3. The answers to the simulation of investment decisions in the context of behavioral economics

\begin{tabular}{ccccccc}
\hline Companies & Accenture & Cisco & IBM & Intel & Microsoft & Oracle \\
\hline $\mathbf{t = 0}$ & 4.83 & 4.80 & 6.45 & 6.27 & 7.72 & 6.63 \\
t=1 & 6 & 5.25 & 7.75 & 7 & 8.75 & 7 \\
Respondent 1 & 7 & 6 & 9 & 7 & 8 & 8 \\
Respondent 2 & 6 & 5 & 9 & 8 & 9 & 7 \\
Respondent 3 & 7 & 4 & 8 & 6 & 9 & 8 \\
Respondent 4 & 4 & 6 & 5 & 7 & 9 & 5 \\
t=2 & 8.25 & 5.5 & 7.5 & 6.75 & 8.5 & 6.75 \\
Respondent 1 & 8 & 8 & 9 & 7 & 8 & 8 \\
Respondent 2 & 9 & 4 & 8 & 7 & 8 & 6 \\
Respondent 3 & 9 & 4 & 8 & 6 & 9 & 8 \\
Respondent 4 & 7 & 6 & 5 & 7 & 9 & 5 \\
t=3 & 6 & 5.25 & 7 & 7 & 8.75 & 8.75 \\
Respondent 1 & 7 & 6 & 8 & 7 & 8 & 8 \\
Respondent 2 & 6 & 5 & 7 & 8 & 9 & 7 \\
Respondent 3 & 7 & 4 & 8 & 6 & 9 & 8 \\
Respondent 4 & 4 & 6 & 5 & 7 & 9 & 5 \\
t=4 & 7.75 & 6 & 4.75 & 7 & 9.25 & 6.25 \\
Respondent $\mathbf{1}$ & 8 & 7 & 8 & 7 & 9 & 7 \\
Respondent 2 & 7 & 5 & 2 & 6 & 10 & 5 \\
Respondent 3 & 9 & 6 & 5 & 7 & 9 & 7 \\
Respondent 4 & 7 & 6 & 4 & 8 & 9 & 6 \\
\hline & & & & Source: our own computation
\end{tabular}

DOI: 10.24818/18423264/55.2.21.10 
An Analysis of Investment Decisions from IC\&T Industry in the Context of Behavioral Economy

\section{Conclusions}

The behavioral economics hypotheses and the prospectus theory proposed by (Kahneman and Tversky, 2000), helped to identify the types of investors according to the factors that influence the decision in investment transactions. Following a rigorous analysis of this research, it was observed that investors generally make the following mistakes in investment decisions: they base their actions on the herd effect, invest in assets they do not know by overestimating their abilities, due to fear or greed. they are in difficulty when it comes to making rational choices or investors enter the stock market with preconceptions that will affect their investment behavior. These conclusions were also observed in the last part of the case study in this research.

The economic system at national or global level can be observed as a complex network characterized by all the activities that are undertaken by the agencies and the economic units that make it up. The stock market, as an important component in an economic system, plays a very important role because it is a trading environment that is closest to the model of a perfectly competitive market respecting the following specific features: atomicity, homogeneity, transparency of information, entry and free exit from the market and mobility of factors of production. Software applications, in the context of the large volume of information and data, help to diagnose economic systems, be they at the level of the national economy, the stock market or at the company level.

In the first part of the case study, an analysis was performed using the $\mathrm{R}$ Studio and Altreva Adaptive Modeler software tool in which the evolution of profitability and closing prices for 6 of the largest IT companies in the world, considered as Complex Adaptive Systems, was determined: Accenture, Cisco, Intel, IBM, Microsoft and Oracle. The analysis was performed for the period 03/01/2012 - 22/05/2020 and we identified the shocks that occurred on the capital market and the fluctuations caused by them.

The last part of the case study consisted of questioning 4 investors, who were asked to give the companies grades on a scale from 1 to 10 , in different contexts, formulating several scenarios. The results revealed that Microsoft's shares were preferred in all cases, even in the context of incomplete information on the investment process. However, for the other companies analyzed, the information provided in addition to each scenario had a significant impact on the previous elections, with the respondent questioning the initial choice. Thus, the timing and context of choosing a decision greatly influences the trajectory of investment preferences among agents and the way one of them behaves can influence under certain conditions and decisions of other agents.

DOI: $10.24818 / 18423264 / 55.2 .21 .10$ 
Nora Chiriță, Cristian Ciurea, Ionuț Nica

\section{REFERENCES}

[1] Chirita, N., Nica, I. (2019), Cibernetica Firmei. Aplicatii si Studii de Caz. Economica Publishing;

[2] Chirita, N., Nica, I. (2020), Analysis of the Impact Generated by COVID-19 in Banking Institutions and Possible Economic Effects; Theoretical and Applied Economics, No.3/2020 (624), Spring;

[3] Goodwin, N., Harris, J.M., Nelson, J.A., Raikarnikar, P.A., Roach, B., Torras, M. (2013), Microeconomics in Context. Routledge;

[4] Hommes, C. (2012) Behavioral Rationality and Heterogeneous Expectations in Complex Economic Systems. Cambridge University Press;

[5] Kahneman, D., Tversky, A. (2000), Choices, Values, and Frames. Cambridge

University Press;

[6] Lewis, L., Haviland-Jones, J.M., Feldman Barrett, L. (2008), Handbook of

Emotions. The Guilford Press;

[7] Lowe, R. A., Teece D. J. (2001), Diversification and Economies of Scope. International Encyclopedia of the Social \& Behavioral Sciences;

[8] Minton, E.A., Kahle L.R. (2013), Belief Systems, Religion, and Behavioral

Economics: Marketing in Multicultural Environments. Business Expert Press;

[9] Nica, I., Chirita, N. (2020), Conceptual Dimensions Regarding the Financial

Contagion and the Correlation with the Stock Market in Romania. Theoretical and Applied Economics, No.1/2020 (622), Spring;

[10] Scarlat, E., Chirita, N. (2019), Cibernetica Sistemelor Economice. Economica;

[11] Smith, A. (2007), Theory of Moral Sentiments. Dover Publications Inc.;

[12] Trémolière, B., De Neys, W. (2014), When Intuitions Are Helpful: Prior Beliefs

Can Support Reasoning in the Bat-and-Ball Problem. Journal of Cognitive

Psychology, 26:4, 486-490;

[13] Tversky, A., Kahneman, D. (1974), Judgment under Uncertainty: Heuristics

and Biases. Science;

[14] Zeliler, K., Teitelbaum, J. (2018), Research Handbook on Behavioral Law and Economics, Elgar;

[15] Mocanu, M., Ciurea. C. (2019) Developing an Index Score for the Internal Auditor Profile in Romania Based on Real Data Analysis: Economic Computation and Economic Cybernetics Studies and Research, 2(53), 93 - 111;

[16] Accenture. Available online: https://www.accenture.com/ro-en (accessed on 16 August 2020);

[17] Cisco. Available online: https://www.cisco.com/ (accessed on 16 August 2020);

[18] IBM. Available online: https://www.ibm.com/ro-en (accessed on 16 August 2020);

[19] Intel. Available online: https://www.intel.com/content/www/us/en/homepage.html (accessed on 16 August 2020);

[20] Microsoft. Available online: https://www.microsoft.com/ro-ro/ (accessed on 16 August 2020);

[21] Oracle. Available online: https://www.oracle.com/index.html (accessed on 16 August 2020).

DOI: $10.24818 / 18423264 / 55.2 .21 .10$ 